\title{
Newcomer integration in knowledge communities: development of the strat-I- Com questionnaire for MMORPG-based communities
}

Nicolae Nistor ${ }^{1,2}$

\begin{tabular}{l}
\hline Correspondence: \\
nic.nistor@uni-muenchen.de \\
${ }^{1}$ Faculty of Psychology and \\
Educational Sciences, \\
Ludwig-Maximilians-Universität, \\
Leopoldstr. 13, D-80802 Munich, \\
Germany \\
${ }^{2}$ Richard W. Riley College of \\
Education and Leadership, Walden \\
University, Minneapolis, USA
\end{tabular}

Correspondence: Educational Sciences,

Ludwig-Maximilians-Universität,

${ }^{2}$ Richard W. Riley College of University, Minneapolis, USA

\begin{abstract}
Players of massively multiplayer online role-playing games (MMORPG) build online knowledge communities that can serve as learning environments for informal adult learning. Hence, newcomer integration in MMORPG player communities can be regarded as a first step in an informal learning process. Newcomer integration strategies have been identified in face-to-face communities, but not yet in MMORPG-based communities. Extending the previous findings and providing quantitative models of specific processes may enhance the development of smart technologies. With this aim, the present research proposes and validates questionnaire survey scales that quantitatively explore the process of newcomer integration in German MMORPG player communities. Two correlational studies within samples with a total of $N=276$ participants were conducted, allowing the identification of five reliable scales (recruitment, knowledge assessment, negative welcome, modeling and consistent training strategies) in the first study and four reliable scales (centrality, recruitment evaluation, monitoring and evaluation of newcomer integration) in the second. The perceptions of newcomer integration strategies were correlated with participants' gender, age and community exposure time. These perceptions were further correlated with participants' centrality and sense of community. The findings add to knowledge communities research and make headway in smart community technology development by suggesting quantitative models for social processes in MMORPG communities. Follow-up research will further explore newcomer integration employing automated analysis procedures with cross-sectional as well as longitudinal research designs.
\end{abstract}

Keywords: Knowledge communities, Massively multiplayer online role-playing games (MMORPG) communities, Newcomer integration strategy

\section{Introduction}

With the explosive development of online gaming technologies, including the Massively Multiplayer Online Role-Playing Games (MMORPG), an increasing number of MMORPG player communities appear. From an educational perspective, MMORPG player communities may be a place for constructing, sharing and applying knowledge. While, at cognitive-academic level, the domain knowledge directly required, negotiated and constructed in actual MMORPGs (such as World of Warcraft and similar games)

(C) 2016 Nistor. Open Access This article is distributed under the terms of the Creative Commons Attribution 4.0 International License (http://creativecommons.org/licenses/by/4.0/), which permits unrestricted use, distribution, and reproduction in any medium, provided you give appropriate credit to the original author(s) and the source, provide a link to the Creative Commons license, and indicate if changes were made. 
may have limited significance, at socio-emotional identity development level the MMORPG usage reveals highly significant educational outcomes (Iacovides et al. 2014; Lemke et al. 2015). For instance, players describe their team experiences as "jointly hard work for hard fun" (Chang and Lin 2014, p. 129), thus pointing at strong involvement and motivation to collaborative problem solving. Player identity, considered in MMORPG social context and in the framework of Lave and Wenger (1991) participative identities, is correlated with learning from gaming experiences (Hopp et al. 2015; Iacovides et al. 2014). These considerations strongly suggest that MMORPG environments support informal learning in knowledge communities (KCs; Lave and Wenger 1991; Scardamalia and Bereiter 2014; Wenger 1998).

Therefore, newcomer integration in MMORPG-based communities may be regarded as a first step in an informal learning process, hence significant for educational research. Yet, little is known about newcomer integration in KCs in general (Eberle et al. 2014), and even less in online environments such as MMORPG-based KCs (Li et al. 2015). A deeper knowledge about newcomer integration in MMORPG KCs may inform smart learning community research and contribute to the development of technologies that make gamebased learning environments "smart" (Giovannella et al. 2014; Li et al. 2015; Lui et al. 2011; Murillo Montes De Oca et al. 2014; Scardamalia and Bereiter 2014; Xia et al. 2013).

In this vein, the studies presented in the following propose and validate an assessment instrument for newcomer integration strategies, applying it in a correlational research design within MMORPG environments, in this way differing from comparisons between MMORPG and face-to-face communities (as reviewed by, e.g., Erhel and Jamet 2013). The proposed instrument provides results that are in line with previous educational research focused on KCs (Eberle et al. 2014; Nistor 2013; Nistor and Fischer 2012; Nistor et al. 2014, Nistor et al. 2015a, Nistor et al. 2015b, Nistor et al. 2015c; Scardamalia and Bereiter 2014) and MMORPG (Chang and Lin 2014; Hopp et al. 2015; Iacovides et al. 2014; Lemke et al. 2015; Zhong 2011). The insight gained by using this instrument suggests further developments of smart learning environments. The validity of the results is limited by the nature of the study, such that causal relationships between MMORPG design elements and community outcomes are outside the scope of these studies' and may be investigated in follow-up research.

\section{Theoretical background}

\section{Knowledge communities}

Knowledge communities (KCs) are groups of mutually engaged people communicating online over longer periods of time, and sharing interests, knowledge and activities. Research points at KCs, either online or traditional, as particularly effective environments for informal adult learning (Lave and Wenger 1991; Nistor 2010; Scardamalia and Bereiter 2014; Wenger 1998). The participation outcomes in KCs include the acquisition of skills and applicable knowledge (Lave and Wenger 1991; Scardamalia and Bereiter 2014; Wenger 1998), participants' positive self-evaluation and development towards expert status (Eberle et al. 2014; Lave and Wenger 1991), and the emergence of a sense of community (McMillan and McMillan 1986; Nistor et al. 2015c). KCs are characterized by their socio-cognitive structure that includes central, active and peripheral members (Lave and Wenger 1991; Wenger 1998). Identity within KCs typically develops from newcomer and novice to old- 
timer and expert. A particular case of KCs are online knowledge communities (OKCs) built by players of massively multiplayer online role-playing games (MMORPG) that displays similar socio-cognitive structures, processes and outcome like traditional KCs (Zhong 2011).

\section{Newcomer integration in knowledge communities}

The existence of a $\mathrm{KC}$ primarily depends on its members that should be available in sufficient number in order to carry on the community practice at a certain qualitative level. Newly established KCs need to reach a critical mass (Cothrel and Williams 2000; Markus 1987) to become functional. Longer established, mature KCs need to compensate for members leaving the group, and to further develop. In both cases, KCs need to attract and integrate new members in order to survive and develop (Barab et al. 2003; Wenger 1998). This requirement is particularly critical for MMORPG-based KCs that are built around technological artifacts (i.e., online games) with a relatively short lifetime (Chen et al. 2006).

KC theorists (Lave and Wenger 1991; Scardamalia and Bereiter 2014; Wenger 1998) regard newcomer integration as laying in the nature of social interactions and being essential for the economy of a community. Nistor et al. (2015a), Nistor et al. 2015b; Nistor et al. 2016 in press) propose a more analytic view, hypothesizing that newcomer integration is a part of the community practice and discourse; therefore it is tightly connected with the established community dialog quality. This emphasizes the influence of communication media on newcomer integration in KCs, as its usage changes the affordances and construction costs of a common knowledge ground between KC members (Brennan and Lockridge 2006), thus making the evaluation of others (Walther 2011) and the coordination of mutual activities more time consuming and effortful (Straus and McGrath 1994). In consequence, members of media-based KCs may apply similar social interaction and communication strategies as in face-to-face settings, however adapting them to the mediated environment, e.g., by choosing more persistent media (or media features) to exchange and display the more persistent information, and less persistent but faster media for the negotiation of meaning (Dillenbourg and Traum 2006).

Not every person will fit a community. New community members are expected to meet certain requirements if they are to be accepted as legitimate participants (Lave and Wenger 1991). Some communities may even pose high obstacles for newcomers to enter (e.g., Merriam et al. 2003), which may ensure not only a minimum of newcomer aptitudes, knowledge, and skills at the beginning of the membership, but also a higher level of participation during the membership (Eberle et al. 2014). A higher participation level strengthens the community and makes it more productive. At the individual level, higher participation leads to a more central position in the community, which fulfills the ideal trajectory from the periphery to the center of the community (Lave and Wenger 1991; Nistor and Fischer 2012).

Eberle et al. (2014) explored the participation support structures for newcomers in university student councils and identified a number of newcomer integration strategies as follows. 
- Recruitment strategies comprise advertising and offering general information about the community, including the ways to get in contact with it, in order to attract newcomers.

- Offering opportunities for participation opens the entrance of a community and supports the newcomers to participate according to their wishes and aptitudes.

- Accessibility of community knowledge enables individual participation at all levels, from the peripheral to the central participation, and may complement recruitment strategies.

- Positive welcoming strategies accompany a newcomers' first contact with the community. They are meant to foster newcomers' gratitude towards the community and their interest to acquire specific community knowledge.

- Negative welcoming strategies are initiations confronting newcomers with their own shortcomings, which aim to show them the need to attain a higher level of knowledge and skills to become full community members.

- Sponsoring newcomers consists of an existing member bringing new members into the community, serving as a contact person, taking care of him/her, and taking the responsibility for his/her behavior in the community.

- Encapsulating newcomers means encouraging them to spend time dedicated to the community and in separation from potentially distracting influences.

- Modeling may be performed by senior community members who want to offer role models, i.e., to show newcomers how to behave according to community norms.

- Consistent training may keep the learning process of newcomers constant, in line with a shared idea about the prerequisites and right behavior of newcomers.

- Monitoring newcomer behavior supposes constant observation against the background of established community rules and standards.

- Knowledge assessment complements monitoring by judging newcomers' knowledge about the community and its practice.

Yet, little is known about the application of newcomer integration strategies in diverse $\mathrm{KCs}$, and even less about the corresponding media influences such as those occurring in MMORPG-based communities. For instance, in MMORPGs, newcomers may perceive the way oldtimers receive and welcome them as more negative, due to restrained social cues and to insufficiently shared knowledge about the community practice (Walther 2011). Participants' gender may influence their perceptions of newcomer integration, as female users often display more participation stability (e.g., Homer et al. 2012; Nistor 2013). Also, participants' exposure time to the community may sustain knowledge construction and sharing (Chang and Lin 2014; Hopp et al. 2015), and thus extend individual skills and develop a more central member identity. A more central participation, in turn, may lead to more accurate perceptions of the community practice (Lave and Wenger 1991; Nistor and Fischer 2012), including newcomer integration. Participants' sense of community may increase in time due to increasing socio-emotional interpersonal knowledge, or it may decrease due to a less enthusiastic and more realistic view of the KC (Nistor et al. 2015c).

Towards MMORPG communities as smart learning environments

Conceptualizing MMORPG communities as smart learning environments may start by understanding the attribute "smart", which has been used as an attribute of spaces, 
such as classrooms, cities, and communities. Smart classrooms use technologies to assist in activities such as collaborative inquiries and knowledge construction. Technology enables the interactions of student groups and, at the same time, provides data on the learning process, focusing on these interactions. Thus, learning is being monitored, analyzed, and the extracted information can be used as feedback to improve learning (Lui et al. 2011). In smart cities, technology is used to empower the inhabitants by focusing on their skills, providing them with relevant feedback, and thus creating a state of collaborative and convergent actions aimed at satisfying (and stimulating) the needs of the inhabitants (Giovannella et al. 2014). Smart communities are interconnected groups of people and technological objects, in which both are monitored resulting in the possibility to deliver "smart services", i.e., feedback given to improve the community overall (Xia et al. 2013). De Oca Murillo Montes et al. (2014) synthesize these definitions stating that smart environments share three common elements: participants (including groups), collaboration, and technology. Further on, the role of technology is both to enable specific processes, and to monitor the entity with bottom-up data that can prompt feedback to the same processes.

Looking back at MMORPG communities, they evidently entail the three elements, i.e., participants and groups, collaboration, and technology. Furthermore, as success in playing the game largely relies on building and developing players' communities, technology may (1) enable OKC development by mediating perceptions, communication and social interactions in the MMORPG environment, and (2) monitor and analyze the OKC development, and provide players with bottom-up feedback. Computer-mediated interactions provide large amounts of data that describe the OKC dynamics. Analyzing this data requires understanding OKC dynamics so far that computational tools will be made available to monitor the OKC development, predict future social behavior or learning, and inform certain interventions (Buckingham Shum and Ferguson 2012). However, little is known about newcomer integration in KCs, and even less in OKCs. Therefore, the present research starts from one of the few quantitative studies exploring newcomer integration in KCs, proposed by Eberle et al. (2014), and extends it to MMORPG communities. The findings are aimed to deepen the understanding of $\mathrm{KC}$ processes, especially from a quantitative perspective, and to add to current research on smart communities (De Oca Murillo Montes et al. 2014).

\section{Research questions and methodology}

Against the background of the theoretical considerations described above, the following research questions were examined (Fig. 1):

RQ1. Which newcomer integration strategies do players perceive in their MMORPG community? How far are these correlated with demographic data, and in particular with gender, age and community exposure time?

RQ2. Are community outcomes correlated with the perceived newcomer integration strategies?

Accordingly, two quantitative, correlational, survey-based studies with one-shot cross-sectional data were conducted in different player communities. Study 1 was a first attempt to examine MMORPG players' perceptions of newcomer integration strategies. 


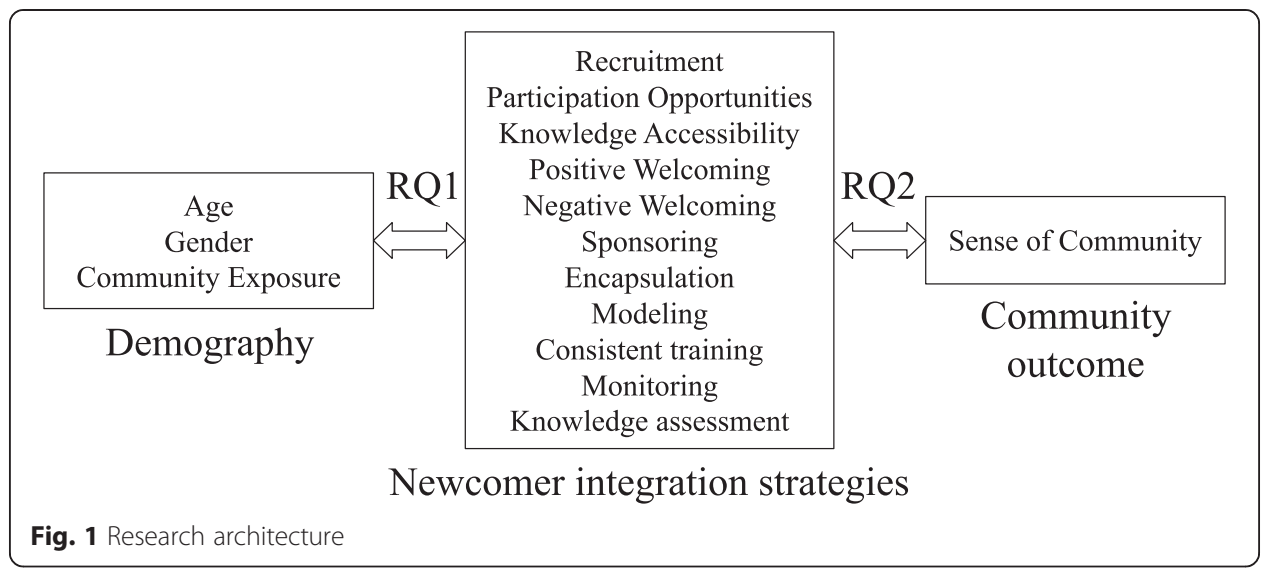

Afterwards, a more accurate examination took place in Study 2, while refining the data collection instruments and overcoming the first study limitations mentioned below.

\section{Setting}

Several MMORPGs were settings of the examined communities, all of them displaying a number of common features. The participants could enter and leave the game anytime. Game participation involved controlling an avatar in a fantasy world populated, e.g. in "World of Warcraft", with dragons, gryphons, elves, zombies, werewolves, a world in which steam-powered automata, spaceships, time travel machines, etc. could be operated. The avatars embodied characters of different races (e.g., orcs, trolls, dwarves or humans) and exercised professions (e.g., tailor, blacksmith, or miner, as in "World of Warcraft"), which allowed them to acquire skills and complete quests in order to earn points and move to higher game levels while outperforming other players. This progression was the primary goal of the games. A further goal consisted in the accumulation of wealth, i.e., resources such as money and weapons. For instance, in "Guild Wars 2", the participants could exercise eight different crafting disciplines and construct weapons with which they could combat with enemies and monsters.

The game goals could be better achieved by collaboration between players, e.g. by trading resources to achieve certain goals, or building teams to fight a powerful enemy. Most MMORPGs included communication tools and support for in-game guilds or clans (e.g., forums and guides for specific roles), and sometimes teamwork was even a request within the game. While collaborating, some players could, e.g., protect others from damage ("tanking"), "heal" damage done to friends, or damage enemies. As a special role, the game moderator or master accessed additional features and game-related information in order to supervise the game world. The social context created by such mediated interaction and communication, and the resources of the game world allowed player groups (so-called "guilds" or "clans") to develop own, extensive narratives, and relatively complex social structures.

\section{Participants}

As a preliminary study, Study 1 was conducted in a MMORPG community of approx. 500 German players of the game "Guild Wars 2". The participant sample consisted of 
$N=123$ players, 106 male and 16 female (1 player did not answer the gender question), aged on average $M=25.1$ years $(S D=8.2)$. Males were on average younger $(M=24.1$, $\mathrm{SD}=7.5)$ than females $(\mathrm{M}=31.9, \mathrm{SD}=9.9)$, and the difference was statistically significant with $\mathrm{F}(1,118)=12.765, p=0.001$. The players had been exposed to their communities for $\mathrm{M}=8.44$ months $(\mathrm{SD}=2.52)$, with no significant difference between genders.

In order to reach a higher setting diversity and to refine the research instrument, Study 2 was performed in various German player communities built on different games, i.e., "Guild Wars 2" as in the previous study, as well as "Battlefield 4", "Counter Strike", "The Elder Scrolls Online", "Star Wars: The Old Republic", "World of Warcraft", "Age of Conan", "League of Legends", and "World of Tanks". The second sample consisted of $N=153$ players, 123 male and 30 female, aged on average $M=29.4$ years $(S D=5.0)$, with no significant age difference between genders. The players had been exposed to their communities between 1 and 12 months $(M=2.44, S D=2.52)$. Female players had been exposed to their communities for a longer time $(M=7.12, S D=6.20)$ than males $(M=4.60$, $\mathrm{SD}=1.84)$, and the difference was significant with $\mathrm{F}(1,151)=8.962, p=0.003$.

\section{Data collection instruments}

In both studies, data was collected by questionnaire survey. The preliminary version of the Strat-I-Com questionnaire was developed for Study 1, deriving the newcomer integration scales from the definitions provided in the theoretical framework (Eberle et al. 2014):

- the Recruitment strategies scale (e.g., "To enter our guild, new players must be selected")

- the Knowledge Assessment scale (e.g., "New members are put to trial with respect to their game skills")

- the Negative Welcoming strategies scale (e.g., "New members must successfully complete a difficult ritual in order to enter our guild")

- the Modeling scale (e.g., "I often act as an example to new players");

- the Consistent Training scale (e.g., "Periodical training and performance exercises are indispensable for guild success")

Additionally, the Sense of Community scales (social and learning components) developed by Rovai et al. (2004) were employed. The mentioned scales proved reliable with Cronbach's $\alpha$ between 0.70 and 0.86 . Further integration strategy scales were tested according to literature mentioned above, however they proved insufficiently reliable, hence they were disregarded. The complete questionnaire is provided in Table 1.

For Study 2, the preliminary questionnaire version was further developed to the Strat-ICom 2015 questionnaire. Here, the Recruitment strategies, Negative Welcome, Modeling, Consistent Training and Sense of Community (social component) scales mentioned above were used in the same form. Three additional scales were developed:

- the Monitoring scale (e.g., "I always look very carefully at new players before I play together with them") 
Table 1 Preliminary version of the Strat-I-Com questionnaire with scale reliabilities (Study 1)

\begin{tabular}{|c|c|c|}
\hline Scale & Items & Cronbach's a \\
\hline \multirow[t]{4}{*}{ Recruitment } & My guild actively searches for new members. & \multirow[t]{4}{*}{0.71} \\
\hline & $\begin{array}{l}\text { We involve new members only after a ritual that is well known } \\
\text { and practiced in our guild. }\end{array}$ & \\
\hline & To enter our guild, new players must be selected. & \\
\hline & $\begin{array}{l}\text { I require new players to perform successfully before they get } \\
\text { integrated into the guild. }\end{array}$ & \\
\hline \multirow[t]{4}{*}{ Knowledge assessment } & I expect a performance boost from new players. & \multirow[t]{4}{*}{0.86} \\
\hline & $\begin{array}{l}\text { I expect other players to keep up with the necessary background } \\
\text { knowledge. }\end{array}$ & \\
\hline & New members are put to trial with respect to their game skills. & \\
\hline & I observe new players' knowledge and skill acquisition. & \\
\hline \multirow[t]{5}{*}{ Negative welcoming } & $\begin{array}{l}\text { New members must successfully complete a difficult ritual in } \\
\text { order to enter our guild. }\end{array}$ & \multirow[t]{5}{*}{0.77} \\
\hline & Experienced guild members are skeptical about new members. & \\
\hline & Players who do not fit the guild are rejected on the spot. & \\
\hline & New players often receive harsh treatment and stinging rebukes. & \\
\hline & In conflict situations, new players have fewer rights than older ones. & \\
\hline \multirow[t]{4}{*}{ Modeling } & I often act as an example to new players. & \multirow[t]{4}{*}{0.70} \\
\hline & In the presence of new players, I strictly observe the guild rules. & \\
\hline & $\begin{array}{l}\text { My behavior is meant to show new players how to properly } \\
\text { interact with each other. }\end{array}$ & \\
\hline & $\begin{array}{l}\text { In our guild, appropriate behavior is being explained and } \\
\text { demonstrated to new players. }\end{array}$ & \\
\hline \multirow[t]{4}{*}{ Consistent Training } & Increasing performance in the guild is most important to me. & \multirow[t]{4}{*}{0.72} \\
\hline & $\begin{array}{l}\text { Proper attendance of other guild members to guild events is } \\
\text { important to me. }\end{array}$ & \\
\hline & $\begin{array}{l}\text { Periodical training and performance exercises are indispensable } \\
\text { for guild success. }\end{array}$ & \\
\hline & Agreements within the guild are absolutely necessary. & \\
\hline
\end{tabular}

- the Integration Strategy Evaluation scale (e.g., "I am satisfied with the way my players' community recruits new members")

- and the Self-Evaluation of Player Competence scale (e.g., "I am one of the best players in our community")

For a more rigorous validation, an exploratory factor analysis was performed starting from all questionnaire items that addressed newcomer integration. After excluding from the initial 29 items those with commonalities below 0.7, and those with loadings over 0.4 on two or more factors, ten items remained, and four principal components were identified, accounting for $77 \%$ of the total variance. The new scales were built of different items than the original scales. Observing the item wording and Eberle et al.'s (2014) approach, the new scales were named

- Centrality

- Recruitment Evaluation

- Monitoring

- Evaluation of Newcomer Integration 
Their factor loadings and Cronbach's $\alpha$ values are provided in Table 2. In this study, the Sense of Community scale (social component only; Rovai et al. 2004) displayed a reliability of $\alpha=0.78$. Further questions inquired participants' demographical information: age, gender and exposure time in the players' community.

\section{Data collection}

All scales consisted of statements that had to be rated using seven point Likert scales ranging from 1 = very strong disagreement to 7 = very strong agreement. In both studies, the participants were addressed in each examined community through the built-in communication tools and invited to answer the questionnaires online. Study 1 was conducted in June 2014, Study 2 in March 2015. In each 1, 2 weeks after inviting the participants to the survey, a reminder was sent, and after the $3^{\text {rd }}$ week the questionnaires were set offline. Subsequently, the survey data was downloaded and statistically processed using IBM SPSS Statistics version 22.

\section{Findings}

\section{Study 1-RQ1 Perceptions of Newcomer Integration Strategies.}

The results comprised values that covered the entire scale range without floor or ceiling effects. These were high values of sense of community, moderate values of consistent training, modeling and monitoring strategies; and low values of negative welcoming strategies, as displayed in Table 3.

Table 2 Strat-I-Com 2015 questionnaire: Factor loadings and reliabilities of the newcomer integration scales (Study 2; main loadings in bold)

\begin{tabular}{|c|c|c|c|c|c|}
\hline & Centrality & $\begin{array}{l}\text { Recruitment } \\
\text { evaluation }\end{array}$ & Monitoring & $\begin{array}{l}\text { Evaluation of } \\
\text { newcomer } \\
\text { integration }\end{array}$ & Cronbach's a \\
\hline $\begin{array}{l}\text { I actively take on certain tasks during } \\
\text { the game, because I am the most } \\
\text { qualified person to do it. }\end{array}$ & 0.879 & 0.068 & 0.177 & -0.068 & 0.87 \\
\hline $\begin{array}{l}\text { I can and I like to help others, because } \\
\text { I am a good player. }\end{array}$ & 0.848 & -0.124 & -0.022 & 0.210 & - \\
\hline $\begin{array}{l}\text { I participate a lot in our players' } \\
\text { community life. }\end{array}$ & 0.816 & 0.179 & 0.115 & 0.176 & - \\
\hline $\begin{array}{l}\text { I like to collaborate with new players } \\
\text { and to guide them. }\end{array}$ & 0.774 & 0.108 & 0.141 & 0.335 & - \\
\hline $\begin{array}{l}\text { I am satisfied with the way my players' } \\
\text { community recruits new members. }\end{array}$ & 0.077 & 0.911 & 0.046 & 0.090 & 0.76 \\
\hline $\begin{array}{l}\text { I believe that my community could } \\
\text { be more creative when recruiting } \\
\text { new members. }\end{array}$ & 0.060 & 0.869 & -0.081 & -0.225 & - \\
\hline $\begin{array}{l}\text { To enter our players' community, new } \\
\text { members must be selected. }\end{array}$ & 0.087 & -0.111 & 0.901 & 0.153 & 0.77 \\
\hline $\begin{array}{l}\text { Before I invite somebody to my players' } \\
\text { community, s/he must prove him/herself. }\end{array}$ & 0.169 & 0.077 & 0.881 & -0.078 & - \\
\hline $\begin{array}{l}\text { New players can become community } \\
\text { members in a short time. }\end{array}$ & 0.132 & -0.041 & -0.001 & 0.931 & 0.85 \\
\hline $\begin{array}{l}\text { The way new members are integrated } \\
\text { into the community is appropriate. }\end{array}$ & 0.265 & -0.088 & 0.071 & 0.863 & - \\
\hline
\end{tabular}


Table 3 Descriptive values of the measured scales (Study 1)

\begin{tabular}{lllll}
\hline Newcomer integration strategies & Min. & Max. & M & SD \\
\hline Recruitment evaluation & 1.00 & 7.00 & 3.16 & 1.69 \\
Knowledge assessment & 1.00 & 7.00 & 3.41 & 1.62 \\
Negative welcoming & 1.00 & 7.00 & 2.14 & 1.09 \\
Modeling & 1.00 & 7.00 & 4.73 & 1.10 \\
Consistent training & 3.00 & 7.00 & 5.73 & 0.98 \\
Sense of community (social) & 3.20 & 7.00 & 6.02 & 0.87 \\
\hline
\end{tabular}

Male players perceived some integration strategies more strongly than female players (Table 4), which was true for Monitoring (male: $\mathrm{M}=3.55$, $\mathrm{SD}=1.64$; female: $\mathrm{M}=2.64$, $\mathrm{SD}=1.16 ; \mathrm{F}(1,119)=4.534, p<.05)$; Negative Welcoming strategies (male: $\mathrm{M}=2.23$, $\mathrm{SD}=1.14$; female $\mathrm{M}=1.64, \mathrm{SD}=.55 ; \mathrm{F}(1,120)=4.083, p=.05$, marginally significant); Recruitment strategies (male: $\mathrm{M}=3.28, \mathrm{SD}=1.74$; female: $\mathrm{M}=2.40, \mathrm{SD}=1.06 ; \mathrm{F}(1$, $120)=3.904, p=.05$, marginally significant); Consistent Training (male: $\mathrm{M}=5.80$, $\mathrm{SD}=.95$; female: $\mathrm{M}=5.31, \mathrm{SD}=1.07 ; \mathrm{F}(1,120)=3.574, p=.06$, marginally significant). There were no significant gender differences in Modeling or in the both components of the Sense of Community scale. Participants' age was weakly and negatively correlated with Monitoring $(r=-.28, p<.01)$, Recruitment $(r=-.23, p<.05)$ and Consistent Training $(r=-.19, p<.05)$.

\section{Study 1-RQ2 Correlates of Newcomer Integration Strategies.}

No significant correlations between perceived integration strategies and any component of Sense of Community could be detected. Community exposure was weakly and negatively correlated with Consistent Training $(r=-0.21, p<.05)$ and Sense of Community (learning component; $r=-0.19, p<.05$ ).

\section{Study 2-RQ1 Perceptions of Newcomer Integration Strategies.}

The measured variables were moderate to high, again covering the entire scale range without floor or ceiling effects. The highest values were measured on the Sense of Community (social component) and Evaluation of Integration Strategies scales; the lowest on the Monitoring and Recruiting Strategy scales. The minimal, maximal,

Table 4 Gender differences in the measured scales (Study 1)

\begin{tabular}{|c|c|c|c|c|c|c|}
\hline & & \multirow[b]{2}{*}{ M } & \multirow[b]{2}{*}{ SD } & \multicolumn{3}{|c|}{ ANOVA } \\
\hline & & & & $\mathrm{df}$ & $\mathrm{F}$ & $p$ \\
\hline \multirow[t]{2}{*}{ Recruitment evaluation } & Male & 3.28 & 1.74 & 1 & 3.904 & 0.050 \\
\hline & Female & 2.40 & 1.06 & 120 & & \\
\hline \multirow[t]{2}{*}{ Knowledge assessment } & Male & 3.55 & 1.64 & 1 & 4.534 & 0.046 \\
\hline & Female & 2.64 & 1.16 & 119 & & \\
\hline \multirow[t]{2}{*}{ Negative welcoming } & Male & 2.23 & 1.14 & 1 & 4.083 & 0.046 \\
\hline & Female & 1.64 & 0.55 & 120 & & \\
\hline \multirow[t]{2}{*}{ Modeling } & Male & 4.73 & 1.10 & 1 & & n.s. \\
\hline & Female & 4.77 & 1.14 & 120 & & \\
\hline \multirow[t]{2}{*}{ Consistent training } & Male & 5.80 & 0.95 & 1 & 3.574 & 0.061 \\
\hline & Female & 5.31 & 1.07 & 120 & & \\
\hline \multirow[t]{2}{*}{ Sense of community (social) } & Male & 5.98 & 0.88 & 1 & & n.s. \\
\hline & Female & 6.27 & 0.72 & 119 & & \\
\hline
\end{tabular}


average values and standard deviations of the measured scales are provided in Table 5.

Similar to Study 1, males perceived two newcomer integration strategies stronger than females: Monitoring Strategies ( $\mathrm{z}$ values male: $\mathrm{M}=0.14, \mathrm{SD}=0.99$; female: $\mathrm{M}=-0.56$, $\mathrm{SD}=0.84 ; \mathrm{F}(1,151)=12.777, p=0.000)$, and Recruitment Evaluation strategies ( $\mathrm{z}$ values male: $\mathrm{M}=0.08, \mathrm{SD}=1.02$; female: $\mathrm{M}=-0.27, \mathrm{SD}=0.80 ; \mathrm{F}(1,151)=4.228, p=0.041)$. No significant gender differences were found in terms of Centrality, Evaluation of Integration Strategies, and Sense of Community (Table 6).

Participants' age was weakly and negatively correlated with their Sense of Community (social component; $r=-0.27, p=0.001)$, Centrality $(r=-0.27, p=0.001)$, and Monitoring strategies $(r=-0.16, p=0.046)$.

\section{Study 2-RQ2 Correlates of Newcomer Integration Strategies.}

Several weak to moderate, positive correlations were found between the measured variables (Table 7). Participants' Centrality correlated with the perception of newcomer integration strategies, in particular with the Evaluation of Integration Strategies ( $r=0.39$, $p<0.000)$ and with Monitoring strategies $(r=0.26, p<0.01)$. Sense of Community (social component) correlated with the Evaluation of Integration Strategies $(r=0.46, p<0.000)$, Centrality $(r=0.45, p<0.000)$ and Monitoring strategies $(r=0.28, p<0.000)$. Community Exposure Time was positively correlated with Monitoring strategies $(r=0.38, p<0.01)$, Centrality $(r=0.35, p<0.01)$ and Evaluation of Integration Strategies $(r=0.31, p<0.01)$.

\section{Discussion}

The presented research explored newcomer integration in various MMORPG communities of German players. In this vein, the Strat-I-Com 2015 questionnaire was developed and validated based on Eberle et al.'s (2014) work. Thus, the present study was successfully positioned in the quantitative research of knowledge communities (Nistor and Fischer 2012), particularly in the actual research on legitimate peripheral participation (Eberle et al. 2014; Lave and Wenger 1991), and newcomer integration in existing socio-cognitive structures (Nistor et al. 2014, Nistor et al. 2015a, Nistor et al. 2015b).

Evidently, MMORPG players form knowledge communities (Chang and Lin 2014; Nistor 2010; Zhong 2011) by building groups that share interests, goals and practice, developing a common history, and collaboratively constructing knowledge and "ways of doing things". Evidence of such socio-cognitive structures could be found especially in the study participants' common practice (i.e., playing MMORPG continuously and for a longer time), in their identification with the knowledge communities reflected in the vocabulary (i.e., participants responded positively to questionnaire items that mostly addressed things that happened "in my players community"), and in the measurable development of a sense of community related both to social and to learning aspects (Nistor et al. 2015c).

Table 5 Descriptive values of the measured scales (Study 2)

\begin{tabular}{lllll}
\hline Newcomer integration strategies & Min. & Max. & M & SD \\
\hline Centrality & 1.50 & 7.00 & 5.25 & 1.22 \\
Recruitment evaluation & 1.50 & 7.00 & 5.03 & 1.29 \\
Monitoring strategies & 1.00 & 7.00 & 4.09 & 1.66 \\
Evaluation of integration strategies & 2.00 & 7.00 & 5.56 & 1.05 \\
Sense of community (social) & 2.40 & 7.00 & 5.78 & 0.78 \\
\hline
\end{tabular}


Table 6 Gender differences in the measured scales (Study 2; all z values)

\begin{tabular}{|c|c|c|c|c|c|c|}
\hline & & \multirow[b]{2}{*}{ M } & \multirow[b]{2}{*}{ SD } & \multicolumn{3}{|c|}{ ANOVA } \\
\hline & & & & $\mathrm{df}$ & $\mathrm{F}$ & $p$ \\
\hline \multirow[t]{2}{*}{ Centrality } & Male & 0.07 & 1.04 & & & n.s. \\
\hline & Female & -0.27 & 0.80 & & & \\
\hline \multirow[t]{2}{*}{ Recruitment evaluation } & Male & 0.08 & 1.02 & 1 & 4.228 & 0.041 \\
\hline & Female & -0.33 & 0.86 & 151 & & \\
\hline \multirow[t]{2}{*}{ Monitoring strategies } & Male & 0.14 & 0.99 & 1 & 12.777 & 0.000 \\
\hline & Female & -0.56 & 0.84 & 151 & & \\
\hline \multirow[t]{2}{*}{ Evaluation of integration strategies } & Male & -0.02 & 1.03 & & & n.s. \\
\hline & Female & 0.09 & 0.89 & & & \\
\hline \multirow[t]{2}{*}{ Sense of community (social) } & Male & 0.02 & 1.08 & & & n.s. \\
\hline & Female & -0.08 & 0.58 & & & \\
\hline
\end{tabular}

These knowledge communities deliberately offered newcomers support structures to facilitate their integration in the community and legitimate peripheral support structures. The most pervasive integration strategies the study participants perceived were recruitment, knowledge assessment, negative welcoming, modeling and consistent training in Study 1; and recruitment, monitoring, and evaluation of newcomer integration strategies in Study 2. These findings are consistent with assumptions and observations described by Lave and Wenger (1991), Wenger (1998), Eberle et al. (2014), and (Nistor et al. 2014, Nistor et al. 2015a, Nistor et al. 2015b, Nistor et al. 2016 in press). Recruitment strategies were perceived in both studies, and this can be explained by the economy of MMORPG communities. Such communities are built around technological artifacts that are used for a relatively small number of years, therefore they must quickly reach maturity in order to be functional. Consequently, a functional MMORPG community needs explicit recruiting strategies, as well as further strategies that ensure the participation quality, such as knowledge assessment and monitoring, modeling and consistent training, and evaluation of newcomer integration.

In Study 2, the revised questionnaire enabled another view of newcomer integration after reordering the questionnaire items and redefining the scales. The resulting constructs were centrality, recruitment evaluation, monitoring and evaluation of newcomer integration. Centrality expresses a player's expertise, responsibility and involvement in more difficult activities within the community practice, exactly as originally defined by Lave and Wenger (1991). The last item ("I like to collaborate with new players and to guide them") explicitly connects centrality (also in the sense of social network analysis,

Table 7 Correlations between the measured variables (Study $2 ;{ }^{*} p<0.05,{ }^{* *} p<0.01$, ${ }^{* *} p<0.000$ )

\begin{tabular}{lllllll}
\hline & 1 & 2 & 3 & 4 & 5 & 6 \\
\hline 1. Centrality & & & & & & \\
2. Recruitment evaluation & 0.11 & & & & & \\
3. Monitoring & $0.26^{* *}$ & -0.03 & & & & \\
4. Evaluation of integration strategies & $0.39^{* * *}$ & -0.13 & 0.11 & & & \\
5. Sense of community (social) & $0.45^{* * *}$ & 0.12 & $0.28^{* * *}$ & $0.46^{* * *}$ & \\
6. Age & $-0.27^{* *}$ & -0.07 & $-0.16^{*}$ & -0.11 & $-0.27^{* *}$ \\
7. Community exposure time & $0.35^{* *}$ & -0.10 & $.38^{* *}$ & $0.31^{* *}$ & $0.39^{* *}$ & -0.09 \\
\hline
\end{tabular}


as applied by Nistor and Fischer 2012) to newcomer integration, while the other three items merely imply a comparison between central and highly skilled vs. peripheral and less skilled OKC members. As suggested by previous studies (Lave and Wenger 1991; Nistor and Fischer 2012; Nistor et al. 2015d), the individual community members' centrality is an essential component of their identity in community context, and it is tightly connected with all the processes and strategies that occur in the community. Corresponding to the focus of this study, participants' centrality was correlated with their perceptions of newcomer integration-and probably also with the active use of such strategies. As explained in previous literature (Lave and Wenger 1991; Nistor and Fischer 2012; Nistor et al. 2015d; Wenger 1998), central community members are deeper involved in the community practice, and take on more responsibility, which includes securing the survival and development of the community (Eberle et al. 2014).

The Recruitment Evaluation scale addresses newcomer integration prospectively, and the Evaluation of Newcomer Integration scale retrospectively. Both are evaluative, which, again, implies the tight relationship between central participation and involvement in newcomer integration. Finally, similarly to the integration strategies identified by Eberle et al. (2014), the Monitoring scale addresses established community rules and standards as a reference for newcomer skill evaluation. However, unlike Eberle's original, the scale is not restricted to the skills the newcomers acquire and exercise after integration, but also includes the time before integration, thus synthesizing Eberle et al. (2014) integration strategies Monitoring Newcomer Behavior and Knowledge Assessment.

Evidently, the Centrality scale describes variables that can also be observed during the game, e.g., by the social network analysis of participation. As opposed to these, the Monitoring, the Recruitment Evaluation, and the Evaluation of Newcomer Integration scales address cognitive phenomena that are not directly observable. Nevertheless, they can be reflected in the dialog between involved members, which can, in turn, be captured and analyzed.

The perception of newcomer integration strategies was correlated with participants' individual characteristics. Firstly, a gender specific pattern appeared, such that male players, who made up the majority in the examined communities, more strongly perceived the newcomer integration strategies, in particular newcomers' recruitment, negative welcoming, knowledge assessment, and monitoring. This finding is consistent with previous studies that showed the MMORPG player population as being predominantly male (e.g., Chen et al. 2006; Homer et al. 2012; Zhong 2011), and males taking violent computer games more seriously more than females did (e.g., Williams et al. 2009). Secondly, younger players perceived the newcomer integration strategies to a greater degree than older players. The identified gender and age correlates may be due to status differences (Zhong 2011), or simply to different perceptions of male vs. female and younger vs. older players. Thirdly, community exposure time displayed relatively strong correlations with players' sense of community, which suggests that this essential component of community output increases over time. The finding is consistent with the mainstream community research (Eberle et al. 2014; Lave and Wenger 1991; Nistor et al. 2015c).

As a final observation, the examined newcomer integration strategies were perceived from a double perspective of the study participants: currently as community members, and, at the same time, as former newcomers. This point of view might seem ambiguous or confusing, nevertheless it is in so far legitimate as the phenomenon of newcomer 
integration does not take place only at a certain community layer (e.g., at the periphery), but in the community practice, thus potentially involving all community members. Central and intermediate community members may initiate, monitor, evaluate and approve newcomer integration, while newcomers aim to integrate, access community knowledge and eventually participate in the ongoing practice as full members (Lave and Wenger 1991). Both sides aim to develop a shared understanding of the integration process (sensu Brennan and Lockridge 2006), which is reflected in the proposed survey scales. The assumption that the survey captures common perceptions of all community members may be close to reality, but may also represent a methodological limitation that should be verified and eliminated in future research.

\section{Conclusions}

The Strat-I-Com 2015 questionnaire proved useful for identifying and measuring newcomer integration strategies in MMORPG communities. The findings add to current research on MMORPG knowledge communities (e.g., Zhong 2011), and inform smart community research (De Oca Murillo Montes et al. 2014). However, they are prone to some limitations, as the questionnaire is still, in its actual form, a relatively simple instrument that needs to be further developed and validated. In the presented studies, only some of the applied scales proved reliable; the others (Consistent Training, for instance) may be reformulated and revalidated. Interviews may help to gain more qualitative insight on the phenomenon of newcomer integration and the meaning that community members give to integration strategies. Subjective transversal data may be reinforced by longitudinal and direct observation data. In the longer term, observation data may be replaced by automated dialog and interaction analysis (e.g., Nistor et al. 2014, Nistor et al. 2015a, Nistor et al. 2015b, Nistor et al. 2015d). Causal relationships between MMORPG design elements and community outcomes are outside the scope of these studies' and may be investigated in follow-up experimental research. Finally, as suggested by Eberle et al. (2014), the research agenda may include an investigation of the relationship between newcomer integration strategies and the level of newcomer peripheral participation after integration.

In technology-based educational practice, from a Learning Analytics perspective (e.g., Buckingham Shum and Ferguson 2012), instruments such as the Strat-I-Com 2015 questionnaire enable a deeper insight into newcomer integration processes and strategies. For a next step, the scale structure of the Strat-I-Com 2015 questionnaire suggests that observable variables, such as centrality, can be automatically measured and provided as a bottom-up feedback to the MMORPG players. Whereas variables that cannot be directly observed, such as recruitment evaluation, monitoring, and evaluation of newcomer integration, can be elicited in the dialog between players-to paraphrase Coiera (2000), conversation may be more efficient than computation-and subsequently extracted by automated dialog analysis. Fostering MMORPG community dialog by collaborative computer-supported argument visualization (Iandoli et al. 2014) may also be used in the context of newcomer integration.

Adding such instruments have a strong potential to make game-based learning environments "smart" (Giovannella et al. 2014; Li et al. 2015; Lui et al. 2011; De Oca Murillo Montes et al. 2014; Scardamalia and Bereiter 2014; Xia et al. 2013) by monitoring and sustaining newcomer integration, as well as by recommending appropriate behaviors 
(Nistor et al. 2015a) and productive partners to learners (Nistor et al. 2014, Nistor et al. 2015b, Nistor et al. 2015d) for collaborative knowledge construction.

\section{Acknowledgements}

The author is thankful to his students Stephan Promberger and Dennis Heerdt from the Armed Forces University of Munich who provided valuable contributions to data collection and instrument refinement; and to Ambar Murillo Montes de Oca for proof reading.

Received: 25 November 2015 Accepted: 22 March 2016

Published online: 30 March 2016

References

S.A. Barab, J.G. MaKinster, R. Scheckler, Designing system dualities: characterizing a web-supported professional development community. Inf. Soc. 19, 237-256 (2003)

S.E. Brennan, C.B. Lockridge, Computer-mediated communication: a cognitive science approach in ELL2, in Encyclopedia of language and linguistics, ed. by K. Brown (Elsevier, Amsterdam, 2006), p. 775

S. Buckingham Shum, R. Ferguson, Social learning analytics. Educ. Technol. Soc. 15, 3-26 (2012)

S.M. Chang, S.S. Lin, Team knowledge with motivation in a successful MMORPG game team: a case study. Comput. Educ. 73, 129-140 (2014)

K.T. Chen, P. Huang, C.L. Lei, Game traffic analysis: an MMORPG perspective. Comput. Netw. 50, 3002-3023 (2006)

E. Coiera, When conversation is better than computation. J. Am. Med. Inform. Assn. 7, 277-286 (2000)

J. Cothrel, R. Williams, Four smart ways to run online communities. Sloan Manage. Rev. 41, 81 (2000)

P. Dillenbourg, D. Traum, Sharing solutions: persistence and grounding in multi-modal collaborative problem solving. J. Learn. Sci. 15, 121-151 (2006)

J. Eberle, K. Stegmann, F. Fischer, Legitimate peripheral participation in communities of practice: participation support structures for newcomers in faculty student councils. J. Learn. Sci. 23, 216-244 (2014)

S. Erhel, E. Jamet, Digital game-based learning: impact of instructions and feedback on motivation and learning effectiveness. Comput. Educ. 67, 156-167 (2013)

C. Giovannella, M. Dascălu, F. Scaccia, Smart city analytics: state of the art and future perspectives. Interact. Des. Archit. J. 20, 72-87 (2014)

B.D. Homer, E.O. Frye, J.L. Plass, Gender and player characteristics in video game play of preadolescents. Comput. Hum. Behav. 28, 1782-1789 (2012)

T. Hopp, V. Barker, A. Schmitz Weiss, Interdependent self-construal, self-efficacy, and community involvement as predictors of perceived knowledge gain among MMORPG players. Cyberpsychol. Behav. Soc. Netw. 18, 468-473 (2015)

I. lacovides, P. McAndrew, E. Scanlon, J. Aczel, The gaming involvement and informal learning framework. Simulat. Gaming. 45, 611-626 (2014)

L. landoli, I. Quinto, A. De Liddo, S. Buckingham Shum, Socially augmented argumentation tools: rationale, design and evaluation of a debate dashboard. Int. J. Hum. Comput. St. 72, 298-319 (2014)

J. Lave, E. Wenger, Situated learning: legitimate peripheral participation (Cambridge University Press, Cambridge, UK, 1991)

J. Lemke, R. Lecusay, M. Cole, V. Michalchik, Documenting and assessing learning in informal and media-rich environments (MIT Press, Cambridge, MA, 2015)

Li Y, M Chang, M Kravcik, E Popescu, Kinshuk, N S Chen (eds.), State-of-the art and future directions of smart learning (Springer, New York, 2015)

Lui M, Tissenbaum M, Slotta J D, Scripting collaborative learning in smart classrooms: Towards building knowledge communities, in Proceeding of the International Conference of Computer Supported Collaborative Learning (vol. 1), ed. by H Spada, G Stahl, N Miyake, N Law (International Society of the Learning Sciences, Hong Kong, 2011), p. 430

M.L. Markus, Toward a "critical mass" theory of interactive media universal access, interdependence and diffusion. Commun. Res. 14, 491-511 (1987)

D.W. McMillan, D.M. McMillan, Sense of community: a definition and theory. J. Commun. Psychol. 14, 6-23 (1986)

S. Merriam, B. Courtenay, L. Baumgartner, On becoming a witch: learning in a marginalized community of practice. Adult. Educ. Q. 53, 170-188 (2003)

A. Murillo Montes de Oca, N. Nistor, M. Dascălu, Ș. Trăușan-Matu, Designing smart knowledge building communities. Interact. Des. Archit. J. 22, 9-21 (2014)

N. Nistor, Knowledge communities in the classroom of the future, in classroom of the future, in Orchestrating collaborative spaces, ed. by K. Mäkitalo-Siegl, J. Zottmann, F. Kaplan, F. Fischer (Sense, Rotterdam, 2010), p. 163

N. Nistor, Stability of attitudes and participation in online university courses: gender and location effects. Comput. Educ. 68, 284-292 (2013)

N. Nistor, C.G. Chiru, N. Bresser, Newcomer integration in online knowledge building communities: automated dialogue analysis in integrative vs. non-integrative blogger communities. Interact. Des. Archit. J. 22, 22-33 (2014)

Nistor N, Dascălu M, Stavarache L L, Serafin Y, Trăușan-Matu Ș, Informal learning in online knowledge communities: Predicting community response to visitor inquiries, in Design for teaching and learning in a networked world. $10^{\text {th }}$ European conference on Technology Enhanced Learning, EC-TEL 2015, Toledo, Spain, September 15-18, 2015, Proceedings, ed. by G Conole, T Klobucar, C Rensing, J Konert, E Lavoué (Springer, New York, 2015a), p. 447

N. Nistor, M. Dascălu, L.L. Stavarache, C. Tarnai, Predicting newcomer integration in online knowledge communities by automated dialog analys, in State-of-the art and future directions of smart learning, ed. by Y. Li, M. Chang, M. Kravcik E. Popescu, R. Huang Kinshuk, N.S. Chen (Springer, New York, 2015b), p. 13

N. Nistor, M. Dascălu, Ș. Trăușan-Matu, Newcomer integration in online knowledge communities: exploring the role of dialogic textual complexity, in Proceedings of The 12th international conference of the learning sciences, "transforming learning, empowering learners", (International Society of the Learning Sciences, Singapore, 2016)

N. Nistor, I. Daxecker, D. Stanciu, O. Diekamp, Sense of community in academic communities of practice: predictors and effects. High. Educ. 69, 257-273 (2015c) 
N. Nistor, F. Fischer, Communities of practice in academia: testing a quantitative model. Learning. Culture. Social. Interaction. 1, 114-126 (2012)

N. Nistor, Ș. Trăușan-Matu, M. Dascălu, H. Duttweiler, C. Chiru, B. Baltes, G. Smeaton, Finding open-ended learning environments on the internet: automated dialogue assessment in academic virtual communities of practice. Comput. Hum. Behav. 47, 119-127 (2015d)

A.P. Rovai, M.J. Wighting, R. Lucking, The classroom and school community inventory: development, refinement, and validation of a self-report measure for educational research. Internet. High. Educ. 7, 263-280 (2004)

M. Scardamalia, C. Bereiter, Smart technology for self-organizing processes. Smart Learn. Environ. 1, 1-13 (2014)

S.G. Straus, J.E. McGrath, The interaction of task type and technology on group performance and member reactions. J. Appl. Psychol. 79, 87-97 (1994)

F. Xia, N. Asabere, A. Ahmed, J. Li, X. Kong, Mobile multimedia recommendation in smart communities: a survey. IEEE. Access. 1, 606-624 (2013)

J.B. Walther, Theories of computer-mediated communication and interpersonal relations, in The SAGE handbook of interpersonal communication, ed. by M.L. Knapp, J.A. Daly (Sage, Thousand Oaks, 2011), p. 443

E. Wenger, Communities of practice: learning, meaning, and identity (Cambridge University Press, Cambridge, UK, 1998)

D. Williams, N. Martins, M. Consalvo, J.D. Ivory, The virtual census: representations of gender, race and age in video games. New. Media. Soc. 11, 815-834 (2009)

Z.J. Zhong, The effects of collective MMORPG (massively multiplayer online role-playing games) play on gamers' online and offline social capital. Comput. Hum. Behav. 27, 2352-2363 (2011)

Submit your manuscript to a SpringerOpen ${ }^{\circ}$ journal and benefit from:

- Convenient online submission

- Rigorous peer review

- Immediate publication on acceptance

- Open access: articles freely available online

High visibility within the field

Retaining the copyright to your article

Submit your next manuscript at $\gg$ springeropen.com 